\title{
Familial absence of the pectoralis major, serratus anterior, and latissimus dorsi muscles
}

\author{
T J DAVID* AND R M WINTER† \\ From * the Department of Child Health, University of Manchester; and the Kennedy-Galton Centre for \\ Clinical Genetics, Harperbury Hospital, Hertfordshire.
}

SUMMARY Congenital absence of shoulder girdle muscles is described in three generations of a family. The proband, a 3 year old boy, had absence of the sternocostal head of the right pectoralis major. His father had absence of the left serratus anterior and part of the left latissimus dorsi and his paternal grandfather had absence of the lower two-thirds of the left pectoralis major, with absence of the left serratus anterior and latissimus dorsi muscles. The condition is probably the result of a dominant gene. These observations show that absence of the pectoralis major is part of a wider spectrum of shoulder girdle defects. Where genetic advice is sought by persons with apparently sporadic absence of the pectoralis major, examination of the relatives is necessary.

The Poland anomaly comprises unilateral absence of the pectoralis major combined with an ipsilateral malformation of the hand which usually includes syndactyly. It is currently unclear whether isolated absence of the pectoralis major muscle and the Poland anomaly are part of the same spectrum of defects or are separate entities. ${ }^{1}$ Both are consistently unilateral and both are usually sporadic although familial cases have been recorded. ${ }^{12}$

Other shoulder girdle abnormalities are sometimes overlooked in patients with the Poland anomaly or those with isolated pectoralis absence. These other abnormalities comprise absence of the serratus anterior, the latissimus dorsi, and possibly the infraspinatus muscles, as well as hypoplasia of the scapula itself. $^{3}$ Most of these defects are clinically evident, but a recent report suggests that computed tomography might help to delineate shoulder girdle muscle defects. ${ }^{4}$ These other shoulder girdle defects are of more than academic importance; absence of the latissimus dorsi robs the plastic surgeon of a useful technique for breast or chest wall reconstruction. ${ }^{5} 6$

We report a family, three members of which had a congenitally absent shoulder girdle muscle. As well as providing a further example of familial absence of the pectoralis major, the findings in this family emphasise the need for careful examination of the other shoulder girdle muscles in any genetic studies

Received for publication 11 October 1984. Accepted for publication 12 November 1984. of the Poland anomaly or isolated absence of the pectoralis. The pedigree is shown in fig 1 .

\section{Case reports}

CASE 1

IV.3 was a male infant, the product of the first pregnancy of a 29 year old mother and 30 year old father, who had been married for seven years. No drugs were given in the first trimester, which was complicated only by vaginal bleeding at three months. Normal delivery was at 40 weeks' gestation, birth weight $3.40 \mathrm{~kg}$. Examination at the age of 3 years showed absence of the sternocostal head of the right pectoralis major (fig 2), with flattening of the right rib cage. The hands and arms were normal and

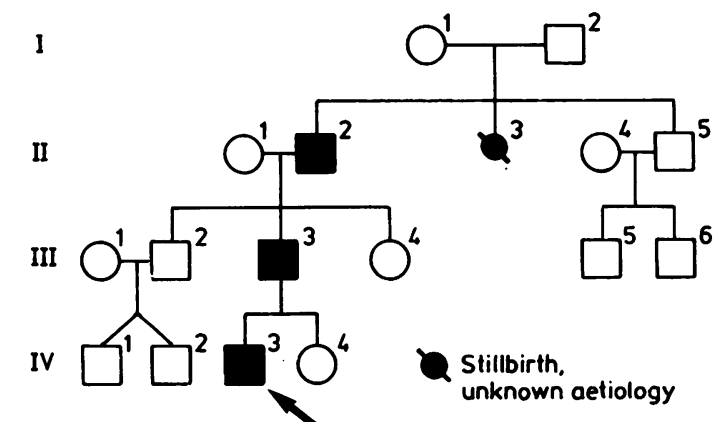

FIG 1 Pedigree of the family. 


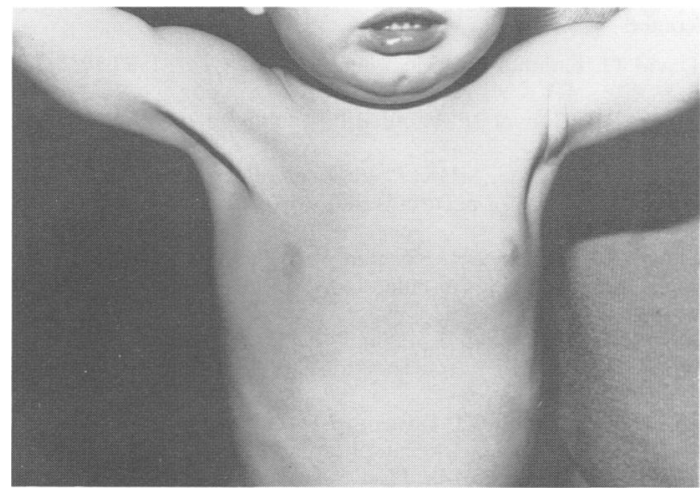

FIG 2 IV.3. The sternocostal head of the right pectoralis major is absent.

symmetrical. The scapula, serratus anterior, and latissimus dorsi muscles were normal.

Examination of a younger sister aged 10 months showed no abnormalities.

\section{CASE 2}

III. 3 was the father of case 1 . No pregnancy details are available. Examination at the age of 33 years showed normal pectoralis major muscles, with normal and symmetrical hands and arms. However there was marked winging of the left scapula, a sloping left shoulder, absence of the left serratus anterior muscle, and partial absence of the left latissimus dorsi muscle.

Examination of his 16 year old sister (III.4), his 35 year old brother (III.2), and the latter's 18 month old twin sons (IV.1 and 2) showed no abnormalities.

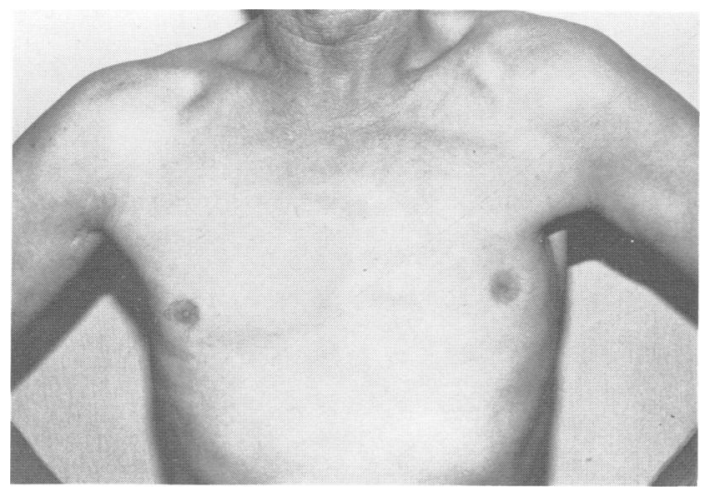

FIG 3 II.2. The lower two-thirds of the sternocostal head of the left pectoralis major is absent.
CASE 3

II. 2 was the father of case 2 . No pregnancy details are available. Examination at the age of 62 years showed absence of the lower two-thirds of the sternocostal head of the left pectoralis major (fig 3 ). The left nipple was inverted. Marked winging of the left scapula was accompanied by absence of the left serratus anterior and latissimus dorsi muscles. The hands and fingers were normal and symmetrical. However, the left forearm was $5 \mathrm{~mm}$ shorter than the right, the circumference of the left upper arm was $17 \mathrm{~mm}$ less than the right, and the circumference of the left forearm at its mid-point was $20 \mathrm{~mm}$ less than the right. These minor asymmetries were thought to be attributable to the fact that the patient was right handed.

There was no history of consanguinity in the family and no other family history of congenital malformations. Case 3 has a younger brother who was not available for examination.

\section{DERMATOGLYPHIC STUDIES}

Finger and palm prints were recorded in all subjects who were examined. All subjects had normal and unremarkable dermatoglyphs. In none were there any of the characteristic features ${ }^{17}$ of the Poland anomaly.

\section{Discussion}

This report describes a boy and his paternal grandfather who both had absence of the pectoralis major. Although the grandfather had a slightly less severe pectoralis defect, he also had associated absence of the ipsilateral serratus anterior and latissimus dorsi. The family had regarded the condition as having skipped the middle generation, but this family study revealed that the boy's father had absence of the serratus anterior and partial absence of the latissimus dorsi. Since absence of these two muscles is well described in association with absence of the pectoralis major, it appears that all three members of the family have a single disorder with varying features. The condition appears to be transmitted as a dominant, either autosomal or $\mathrm{Y}$ linked. Although sibs and cousins with absence of the pectoralis major have been previously described, ${ }^{1}{ }^{2}$ vertical transmission has not (with one dubious exception). However, if one believes that isolated pectoralis absence, isolated unilateral symbrachydactyly, and the Poland anomaly are all part of the same spectrum, then vertical transmission has been observed ${ }^{89}$ in two families.

In view of the presumed genetic basis for the 
pectoralis, serratus, and latissimus muscle absence in the family reported here, it is interesting to note that the defect did not always affect the same side. It was left sided in the grandfather and his son, but right sided in the grandson. Of the seven published reports of familial absence of the pectoralis major or related defects, ${ }^{19-12}$ the defect was on the same side in all affected members in five (right side two families, left side three families), but on different sides in two families. How a single gene or set of genes can operate to affect different sides within the same family is as obscure as the consistent unilaterality of absence of the pectoralis major with or without the Poland anomaly.

Clearly, when examining relatives of patients with the Poland anomaly or allied disorders, this examination needs to include the whole shoulder girdle if minor or atypical shoulder girdle defects are to be detected. While most cases of the Poland anomaly or isolated pectoralis absence are sporadic, ${ }^{1}$ the rare familial cases will be missed without careful examination of relatives, and inappropriate genetic information given.

We thank Dr D Donnai and Dr R W Newton for their help, Professor R B Lowry for sending us a copy of reference 9 and its English translation, and Michelle Turner for typing the manuscript.
References

1 David TJ. Familial Poland anomaly. J Med Genet 1982;19:2936.

2 Lowry RB, Bouvet JP. Familial Poland anomaly. J Med Genet 1983;20:152-4.

${ }^{3}$ Hedge HR, Shokeir MHK. Posterior shoulder girdle abnormalities with absence of pectoralis major muscle. Am J Med Genet 1982;13:285-93.

4 Suzuki T, Takazawa H, Koshino T. Computed tomography of the pectoralis muscles in Poland's syndrome. Hand 1983;15:3541.

5 Hester TR, Bostwick J. Poland's syndrome: correction with latissimus muscle transposition. Plast Reconstr Surg 1982;69:226-33.

${ }^{6}$ Cochran JH, Pauly TJ, Edstrom LE, Dibbell DG. Hypoplasia of latissimus dorsi muscle complicating breast reconstruction in Poland's syndrome. Ann Plast Surg 1981;6:402-4.

7 David TJ, Saad MN. Dermatoglyphic diagnosis of the Poland anomaly in the absence of syndactyly. Hum Hered 1974;24:3738.

${ }^{8}$ Fuhrmann W, Mosseler U, Neuss H. Zur klinik und genetik des poland-syndroms. Dtsch Med Wochenschr 1971;96:1076-8.

9 Mustata N, Vicas E, Petcu P. Sindromul Poland. Viata Med 1976;23:173.

${ }^{10}$ Greif G. Drei falle von congenitalem defekt an der vonderen thoraxwand. MD thesis, University of Greifswald, 1891:28-33.

$"$ Bouvet JP, Maroteaux P, Briard-Guillemot M. Le syndrome de Poland: études cliniques et génétiques - considerations physiopathologiques. Nouv Presse Med 1976;5:185-90.

12 Armendares S. Absence of pectoralis major muscle in two sisters associated with leukaemia in one of them. $J$ Pediatr 1974;85:436-7.

Correspondence and requests for reprints to Dr T J David, Booth Hall Children's Hospital, Charlestown Road, Blackley, Manchester M9 2AA. 